\title{
Preventive Multimodal Analgesia Versus Morphine in Cancer Patients Undergoing Major Abdominal Surgeries
}

\author{
WALAA Y. ELSABEENY, M.D. \\ The Departments of Anesthesia, Pain and Intensive Care, National Cancer Institute, Cairo University
}

\begin{abstract}
Background: Opioids are the corner stone for perioperative analgesia in major surgeries. The aim of this study was to compare the efficacy of preventive multimodal analgesia versus morphine on post-operative pain and total morphine consumption.
\end{abstract}

Aim of Study: To compare the efficacy of preventive multimodal analgesia versus morphine in cancer patients undergoing major abdominal surgeries.

Patients and Methods: This prospective randomized study was done from March 2018 to September 2018 after approval of the institutional board review of National Cancer Institute. Forty cancer patients were randomly allocated in the study; patients were divided into 2 groups; multimodal group $(n=20)$ received Ketamine, magnesium, ketorolac, paracetamol, with TAB (transverse abdominis plane) block before surgical incision and morphine group $(\mathrm{n}=20)$ received morphine sulphate $0.1 \mathrm{mg} / \mathrm{kg}$ before surgical incision.

Results: There was statistically significant difference in intraoperative fentanyl consumption $p$-value $(<0.001)$ and total morphine consumption in the first 24 hours postoperatively $p$-value $(0.001)$ between the 2 studied groups being higher in the morphine group.

Conclusion: Preventive multimodal analgesia has superior analgesic profile than morphine regarding perioperative analgesia and morphine consumption in the first 24 hours post-operatively.

Key Words: Preventive - Multimodal analgesia-Morphine - Post-operative pain-Cancer patients.

\section{Introduction}

UNTREATED post-operative pain can be a significant cause of morbidity following surgical trauma. Acute pain control is essential to avoid long term sequale of untreated pain. These sequale

Correspondence to: Dr. Walaa Y. Elsabeeny, E-Mail: walaa 70s@hotmail.com can affect the process of pain sensitivity, may lead to long term negative impacts on pain neurophysiology and sensitivity. Preventive multimodal analgesia concept targets perioperative pain control through different antinociceptive mechanisms [1].

Opioids are considered the gold standard drugs for post-operative pain control. Morphine is the most commonly used opioid in perioperative settings [2]. However opioid side effects are not always tolerated and can be dose dependent side effects. Applying multimodal analgesia can potentially reduce opioid related side effects through combining smaller doses of opioids with nonopioid analgesics (and adjuvant agents) acting on multiple different sites within the central and peripheral nervous systems $[3,4]$.

Drugs used as a part of multimodal approach for pain control include opioids, nonsteroidal antiinflammatory drugs and acetaminophen. Adding ketamine shows to augment the multimodal analgesic effect especially when magnesium sulphate is added to it [5]. In addition to pharmacological drugs, interventions as peripheral nerve blocks, neuraxial blocks (e.g epidural analgesia) and truncal blocks (e.g Transversus Abdominis Block (TAB), Quadratus Lumborum Block (QLB), rectus sheath block (RB) are successfully used as an approach for multimodal analgesia $[6,7]$.

The analgesic approach should be adjusted and tailored for every patient according to his current and past medical condition, type of surgery aiming to improve the outcome and minimize the side effects [8]

Proper understanding of the mechanisms involved in acute post-operative pain results in evolution from the 'preemptive analgesia' concept into 
another broader concept of 'preventive analgesia'. The difference between preemptive and preventive analgesia depends on the timing of analgesic drug administration [6].

Pre-emptive analgesia refers to analgesia applied before surgical skin incision to prevent acute post-operative pain and modulate central sensitization. Preventive analgesia, aim to modulate nociception throughout the perioperative period leading to reduce post-operative pain along with decreasing post-operative analgesic consumption [9].

Transversus Abdominis Plane block (TAP) can be effectively used as one of the regional modalities for analgesia in abdominal surgeries. Its analgesic effect is thought to be through blocking sensory innervation of the anterior abdominal wall before sensory nerves pierce the muscles for innervation [10].

This study aim was to compare the effect of preventive multimodal analgesia versus morphine in cancer patients undergoing major abdominal surgeries regarding effect on 24 hours post-operative morphine consumption, perioperative pain and possible side effects.

\section{Patients and Methods}

This prospective randomized controlled study was conducted from March 2018 to September 2018 after approval of the Institutional Review Board of the National Cancer Institute (IRB-NCI), Cairo University, IRB no. (201617033.2P). A written informed consent was taken from all patients undergoing the study.

Forty cancer patients aged $18-65$ years with ASA (American Society of Anesthesiology) II-III, referred to the anesthesia department in NCI requiring major abdominal surgeries were included in the study. Patients with coagulation defects, abnormal kidney and liver functions, local infection at site of injection or known allergy to any of the used drugs were excluded from the study.

Upon arrival to the holding area all the patients were monitored by standard monitoring (ECG, pulse oximetry and non-invasive automated arterial blood pressure). Then all patients were premedicated with midazolam (2-3mg IV) after fixation of $20 \mathrm{G}$ cannula. Induction of anesthesia was done by propofol $2 \mathrm{mg} / \mathrm{kg}$, fentanyl $2 \mathrm{t} / \mathrm{kg}$ and rocuronium $0.7 \mathrm{mg} / \mathrm{kg}$ followed by single lumen endotracheal intubation and controlled mechanical ventilation with $50 \%$ Fio2, then after anesthesia was maintained by sevoflurane and rocuronium for both groups.

Patients were randomly allocated into 2 equal groups, 20 patients each. Multimodal group: Received bilateral TAP block, intravenous ketamine $0.5 \mathrm{mg} / \mathrm{kg}$, magnesium sulphate $1 \mathrm{~g}$, NSAID (ketrolac 30mg), paracetamol (perfalgan 1g). Morphine group: Received $0.1 \mathrm{mg} / \mathrm{kg}$ morphine sulphate. In Multimodal group: After induction of general anesthesia patients were positioned in supine position. A SonoSite M-Turbo ultrasound machine with a multifrequency linear probe $6-13 \mathrm{~Hz}$ (FUGIFILM Sonosite, Inc. Bothel, WA 98021, USA) was used. After skin preparation and sterilization, the ultrasound probe was moved across the abdomen from midline laterally to identify fascial plane of transversus abdominis at anterior axillary line between the 12 th rib and iliac crest. An 18-G Tuohy needle was advanced through the skin piercing the external oblique and the internal oblique muscles reaching the fascial plane between the internal oblique and transversus abdominis then after negative aspiration injection of $20 \mathrm{ml}$ of bupivacaine $0.25 \%$ was slowly injected with a maximum dose not exceeding $2.5 \mathrm{mg} / \mathrm{kg}$ bupivacaine.

Starting from induction of anesthesia HR, Spo2 was continuously monitored and SBP, DBP was recorded every 15 minutes. In order to ensure adequate analgesia throughout the operation all patients was closely observed and upon appearance of signs of inadequate analgesia e.g increase in $\mathrm{HR}$ or systolic blood pressure $20 \%$ above the baseline, fentanyl rescue doses of $0.5 \mathrm{t} / \mathrm{kg}$ was supplemented and recorded. Both groups received morphine $0.1 \mathrm{mg} / \mathrm{kg}$ for post-operative pain control when there VAS score $>4$, or paracetamol $1 \mathrm{~g}$ not exceeding $4 \mathrm{~g} / \mathrm{d}$ when VAS score $<4$.

\section{Sample size calculation:}

Sample size was calculated based on the previous paper of El-Dawlatly et al., 2009 [12] in which the morphine consumption within each subject group was normally distributed with standard deviation (4.3). If the true difference in the TAP group and control group means is $25 \%$, we will need to study 20 patients in each group to be able to reject the null hypothesis that the population means of the study groups are equal probability (power) 95\%. The type I error probability associated with this test of this null hypothesis is 0.05 . 


\section{Results}

The two studied groups were comparable in demographic data, duration and type of surgery Tables (1-3)

There was no statistically significant difference between both groups in their systolic and diastolic blood pressure in the holding area and baseline measurements, however there was a statistically significant difference between both groups in the intraoperative period being lower for the multimodal group Figs. $(1,2)$. Both groups showed no statistically significant difference in heart rate measurement and arterial oxygen saturation values (SpO2).

There was a statistically significant difference between both groups in intraoperative fentanyl consumption being lower $(38 \pm 20)$ fo multimodal group than morphine group (78 \pm 36 ) $<0.001$. Total morphine consumption for the first 24 hours post-operatively showed statistically significant difference between the 2 groups being higher in the morphine group $(10 \pm 3) \mathrm{mg} / 24 \mathrm{hrs}$ than the multimodal group $(7 \pm 2) \mathrm{mg} / 24 \mathrm{hrs}, p 0.001$. Time to first dose morphine was statistically longer for the morphine group ( $8 \pm 2)$ hours than the mul-

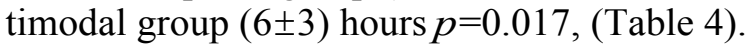

There was no statistically significant difference between both groups in median VAS score within the first 12 hours however; the median VAS score was statistically significant lower in the multimodal group at 18 and 24 hours $(p=0.043,0.028)$ respectively, (Table 5). There were no reported cases of nausea and vomiting in both groups.
Table (1): Age and duration of surgery.

\begin{tabular}{lcclllll}
\hline & \multicolumn{2}{c}{ Multi } & & \multicolumn{2}{c}{ Morphine } & \\
\cline { 2 - 3 } & Mean & SD & & Mean & SD & $p$-value \\
\hline Age (years) & 52 & 8 & & 53 & 8 & 0.701 \\
Duration (minutes) & 125 & 30 & & 123 & 29 & 0.872 \\
\hline
\end{tabular}

SD: Standard deviation, $p \leq 0.05$ is statistically significant, analysis done by independent $t$-test.

Table (2): Patient gender.

\begin{tabular}{lcclllll}
\hline & \multicolumn{2}{c}{ Multi } & & \multicolumn{2}{c}{ Morphine } & \\
\cline { 2 - 3 } & Number & $\%$ & & Number & $\%$ & & -value \\
& & & & & & \\
\hline Gender: & 10 & 50.0 & & 9 & 45.0 & 0.752 \\
Female & 10 & 50.0 & & 11 & 55.0 & \\
Male & 10 & & & & &
\end{tabular}

Table (3): Type of surgery.

\begin{tabular}{lccccc}
\hline \multirow{2}{*}{ Type of surgery } & \multicolumn{2}{c}{ Multi } & \multicolumn{2}{c}{ Morphine } & $p$ - \\
\cline { 2 - 6 } & Number & $\%$ & Number & $\%$ & value \\
\hline - Cancer colon & 7 & 35.0 & 6 & 30.0 & \\
- Cancer pancreas & 5 & 25.0 & 5 & 25.0 & \\
- Anterior abdominal & 2 & 10.0 & 3 & 15.0 & 0.613 \\
$\quad$ wall tumor & & & & & \\
- Renal cell carcinoma & 3 & 15.0 & 2 & 10.0 \\
- Retroperitoneal tumor & 3 & 15.0 & 4 & 20.0 \\
\hline
\end{tabular}

Table (4): Total intraoperative fentanyl, total post-operative morphine consumption and time to first dose analgesic.

\begin{tabular}{lcccccc}
\hline & \multicolumn{2}{c}{ Multi } & & \multicolumn{2}{c}{ Morphine } & \\
\cline { 2 - 3 } & Mean & SD & Mean SD & & value \\
\hline Fentanyl ( $)$ & 38 & 20 & & 78 & 36 & $<0.001$ \\
Morph (mg/24h) & 7 & 2 & & 10 & 3 & 0.001 \\
Time to 1 st analg & 8 & 2 & & 6 & 3 & 0.017 \\
\hline
\end{tabular}

SD: Standard deviation, $p \leq 0.05$ is statistically significant, analysis done by independent $t$-test.

Table (5): VAS score in the first 24 hours post-operatively.

\begin{tabular}{lccccccc}
\hline & \multicolumn{7}{c}{ Multi } \\
\cline { 2 - 6 } & Median & Minimum & Maximum & Median & Minimum & Maximum & $p$-value \\
\hline VAS 0 & 2 & 1 & 4 & 2 & 0 & 4 & 0.657 \\
VAS 2 & 3 & 1 & 4 & 3 & 1 & 8 & 0.132 \\
VAS 4 & 3 & 1 & 7 & 3 & 0 & 8 & 0.420 \\
VAS 6 & 3 & 1 & 7 & 3 & 0 & 7 & 0.923 \\
VAS 8 & 3 & 0 & 7 & 4 & 1 & 8 & 0.545 \\
VAS 12 & 2 & 0 & 8 & 3 & 0 & 8 & 0.248 \\
VAS 18 & 3 & 0 & 4 & 3 & 1 & 4 & 0.043 \\
VAS 24 & 2 & 0 & 4 & 3 & 1 & 6 & 0.028 \\
\hline
\end{tabular}

$p \leq 0.05$ is statistically significant, analysis done by Mann Whitney test. 


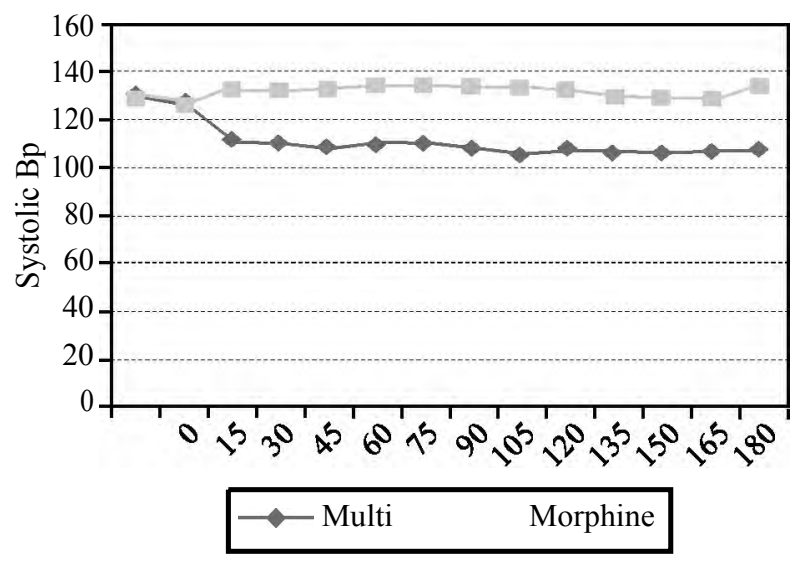

Fig. (1): Systolic blood pressure changes in the two studied groups.

\section{Discussion}

Preventive analgesia targets to control pain throughout the perioperative period, furthermore applying multimodal analgesic approach help in reducing post-operative opioid consumption, as well as playing an important role in Enhanced Recovery After Surgery (ERAS) protocols [13]

The current study results reported that multimodal regimen had higher perioperative analgesic efficacy as well as reduced total post-operative opioid consumption when compared to morphine alone. These results are supported by a populationbased retrospective cohort study done by Cozowicz et al., [14], stating that receiving multimodal analgesic regimen showed to be superior to opioid only analgesia.

Adding non opioid analgesics as Non-Steroidal Anti-Inflammatory (NSAIDs) and paracetamol reduces postoperative morphine consumption. This is in accordance to the results of systematic review done by Maund et al., who found that there is reduction in 24 hours postoperative morphine consumption when NSAIDs, paracetamol were added to Patient Controlled Analgesia (PCA) morphine for post-operative pain control [15].

In 2017 Helander et al., [13], compared 15 institutional multimodal analgesic approaches who implement ERAS protocols. They concluded that paracetamol and NSAIDs are the most commonly used non-opioid analgesics which play an important role in post-operative analgesia with opioid sparing effect, in addition to reduction of post-operative ileus resulting in earlier ambulation.

Adding magnesium sulfate to multimodal regimen reduced perioperative pain and total postoperative morphine consumption. This is in agreement to the results of a meta-analysis done by

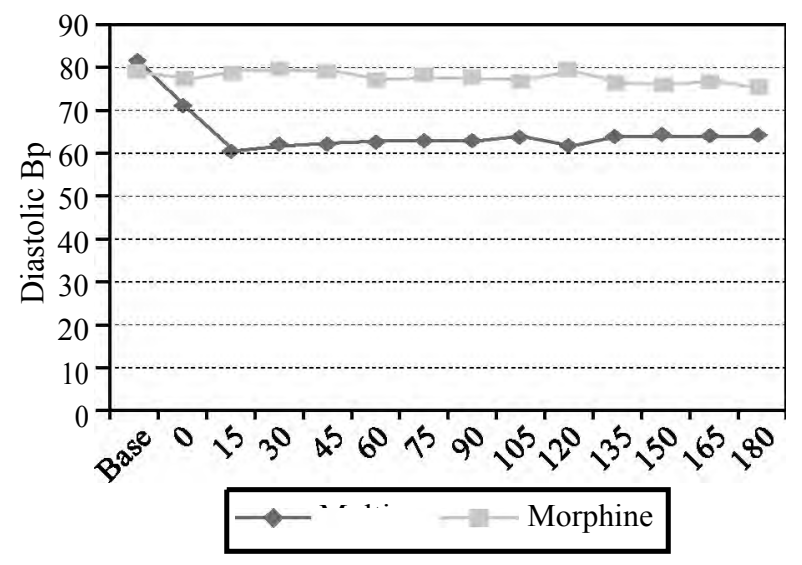

Fig. (2): Diastolic blood pressure changes in the two studied groups.

Oliveira et al., in 2013 [16] who stated that perioperative use of magnesium decreases post-operative pain and can lead to reduction of post-operative opioid consumption. This was supported by the results of more recent studies in different surgical procedures as hepatectomy, laparoscopic gastrectomy and laparoscopic gynecological surgeries [1719]. Using perioperative magnesium has a promising role in reducing post-operative opioid consumption [20].

Using ketamine in low dose can help in reducing perioperative opioid use as well as decreasing the need for long term postoperative opioids [21]. This is supported by a meta-analysis of 5 studies which investigated the effect of preemptive ketamine on postoperative pain [22] . It was reported that ketamine reduced the amount of postoperative morphine consumption as well as prolonging the time for first analgesic requirement additionally it didn't increase the incidence of nausea and vomiting [23]. We didn't report any side effects from low dose ketamine, same was mentioned by Benzon et al who reported no increase in the incidence of ketamine side effects when low doses are used [20].

Providing regional analgesia by Transversus Abdominis Plane block (TAB) enhances analgesia when compared to standard opioid analgesia. It helps in reducing perioperative opioid consumption [12] . Carney et al., stated that adding TAB block to multimodal analgesia resulted in better post-operative analgesia and reduced morphine consumption in patients undergoing total abdominal hysterectomy when compared to placebo effect [24].

\section{References}

1- VERGHESE S.T. and HANNALLAH R.S.: Acute pain management in children. J. Pain. Res., 3: 105-23, 2010. 
2- BUJEDO B.M., SANTOS S.G. and AZPIAZU A.U.: A review of epidural and intrathecal opioids used in the management of post-operative pain. J. Opioid. Manag., 8: 177-92, 2012.

3- ELVIR-LAZO O.L. and WHITE P.F.: Post-operative pain management after ambulatory surgery: Role of multimodal analgesia. Anesthesiol. Clin., 28: 217-24, 2010.

4- VADIVELU N., MITRA S. and NARAYAN D.: Recent advances in post-operative pain management. Yale. J. Biol. Med., 83: 11-25, 2010.

5- HELANDER E.M., MENARD B.L., HARMON C.M., et al.: Multimodal Analgesia, Current Concepts, and Acute Pain Considerations. Curr. Pain. Headache. Rep., 21: 3, 2017.

6- ROSERO E.B. and JOSHI G.P.: Preemptive, preventive, multimodal analgesia: What do they really mean? Plast. Reconstr. Surg., 134: 85-93, 2014.

7- GO R., HUANG Y.Y., WEYKER P.D., et al.: Truncal blocks for perioperative pain management: A review of the literature and evolving techniques. Pain. Manag., 6 (5): 455-68, 2016.

8- FANELLI G., BERTI M. and BACIARELLO M.: Updating post-operative pain management: From multimodal to context-sensitive treatment. Minerva. Anestesiol., 74: 489-500, 2008.

9- VADIVELU N., MITRA S., SCHERMER E., et al.: Preventive analgesia for postoperative pain control: A broader concept. Local. and Regional. Anesthesia, 717-22, 2014.

10- MCDONNELL J.G., O'DONNELL B., CURLEY G., et al.: The analgesic efficacy of transversus abdominis plane block after abdominal surgery: A prospective randomized controlled trial. Anesth. Analg., 104: 193-7, 2007.

11- HUSKISSON E.C.: Measurements of pain. Lancet, 2: 1127-31, 1974.

12- L-DAWLATLY A.A., TURKISTANI A., KETTNER S.C., et al.: Ultrasound-guided transversus abdominis plane block: Description of a new technique and comparison with conventional systemic analgesia during laparoscopic cholecystectomy $\dagger$ British Journal of Anaesthesia, 102: 763-7, 2009.

13- ELANDER E.M., WEBB M.P., BIAS M., WHANG E.E., KAYE A.D. and URMAN R.D.: A comparison of multimodal analgesic approaches in institutional enhanced recovery after surgery protocols for colorectal surgery: Pharmacological agents. Journal of Laparoendoscopic \& Advanced Surgical. Techniques. 1, 27 (9): 903-8, 2017.

14- OZOWICZ C., POERAN J., ZUBIZARRETA N., LIU J., WEINSTEIN S.M., PICHLER L., MAZUMDAR M. and MEMTSOUDIS S.G.: Non-opioid analgesic modes of pain management are associated with reduced postoperative complications and resource utilisation: A retro- spective study of obstructive sleep apnoea patients undergoing elective joint arthroplasty. British Journal of Anaesthesia. Oct., 27, 2018.

15- MAUND E., MCDAID C., RICE S., WRIGHT K., JENKINS B. and WOOLACOTT N.: Paracetamol and selective and non-selective non-steroidal anti-inflammatory drugs for the reduction in morphine-related side-effects after major surgery: A systematic review. British Journal of Anaesthesia, 106: 292-7, 2011.

16- De OLIVEIRA G.S., CASTRO-ALVES L.J., KHAN J.H and NCCARTHY R.J.: Perioperative systemic magnesium to minimize postoperative pain. A meta-analysis of randomized controlled trials. Anesthesiology, 119: 178-90, 2013.

17- MAHMOUD G., SAYED E., ESKANDER A., et al.: Effect of intraoperative magnesium intravenous infusion on the hemodynamic changes associated with right lobe living donor hepatotomy under transesophageal Doppler monitoring randomized controlled trial. Saudi. J. Anaesth., 10: 132-7, 2016.

18- RYU J.H., KOO B.W., KIM B.G., et al.: Prospective, randomized and controlled trial on magnesium sulfate administration during laparoscopic gastrectomy: Effects on surgical space conditions and recovery profiles. Surg. Endosc., 30: 4976-84, 2016.

19- SOUSA A.M., ROSADO G.M., NETO JDE S., et al.: Magnesium sulfate improves postoperative analgesia in laparoscopic gynecologic surgeries: A double blind randomized controlled trial. J. Clin. Anesth., 34: 379-84, 2016.

20- BENZON H.A., SHAH R.D. and BENZON H.T.: Perioperative nonopioid infusions for postoperative pain management. In Essentials of Pain Medicine (Fourth Edition) (pp. 111-6), 2018.

21- EBALLOS, JOSE L., PHILIPP LIRK and JAMES P.: RATHMELL. "Low-Dose Ketamine for Acute Pain Management: A Timely Nudge Toward Multimodal Analgesia." Regional Anesthesia and Pain Medicine, 5: 453-55, 2018.

22- ANG L., ZHANG J., ZHANG Z., ZHANG C., ZHAO D. and LI J.: Preemptive analgesia effects of ketamine in patients undergoing surgery. A meta-analysis. Acta. Cirurgica. Brasileira, 12: 819-25, 2014.

23- EYDARI S.M., HASHEMI S.J. and POURALI S.: The Comparison of Preventive Analgesic Effects of Ketamine, Paracetamol and Magnesium Sulfate on Postoperative Pain Control in Patients Undergoing Lower Limb Surgery: A Randomized Clinical Trial. Adv. Biomed. Res., 6: 134, 2017.

24- CARNEY J., MCDONNELL J.G., OCHANA A., BHINDER R. and LAFFEY J.G.: The transversus abdominis plane block provides effective post-operative analgesia in patients undergoing total abdominal hysterectomy. Anesthesia \& Analgesia, 107 (6): 2056-60, 2008 


\section{التسكين الوقائى متعلدد الوسائط مقارنة بالمورفين

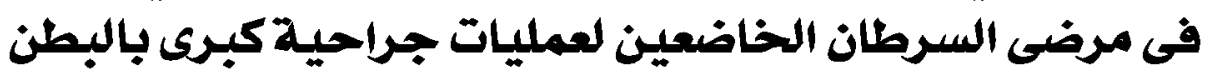

$$
\text { تعتبر العقارات الأفيونية هى حجر الأساس لتسكين الآلام أثناء العمليات الجراحية الكبرى. }
$$

تهدف هذه الدراسة إلى مقارنة جودة التسكين الوقائى متعدد الوسائط مقابل الموففين لتسكين الآلام ما بعد العمليات الجراحية ومعدل أستهلاك المورفين.

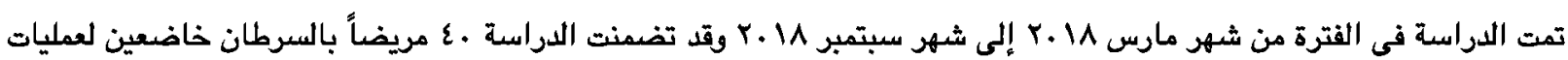

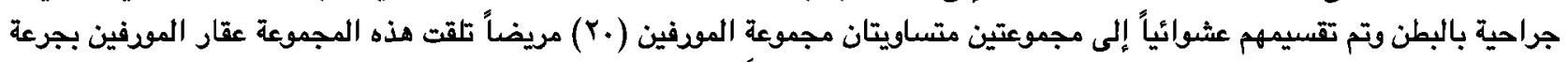

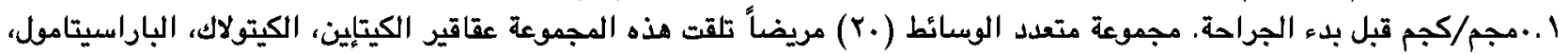

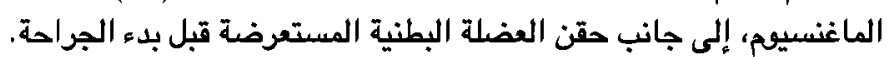

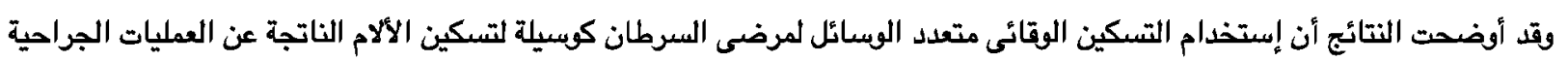

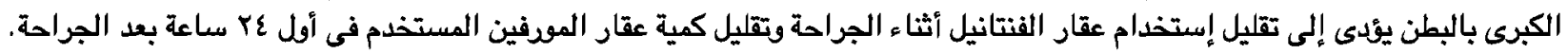

